\section{Evaluation}

Invitations were sent to fourteen students who had failed to register a title for their research project. Two were unable to attend on that afternoon, and of the twelve who accepted the invitation three claimed to have projects but decided to attend the course anyway; four others said that they had tentative ideas for research, while five had no ideas. At the end of the course, nine ( 75 per cent) had firm plans for research, while the remaining three had made tentative plans.

Students gave their opinion of the course on a form which they did not have to sign; nevertheless, comments were uniformly favourable about the course on the whole, and generally favourable about each individual teacher. One student wrote:

'From the point of view of actually tackling research, this course has been more useful than any in the past two years. Talking about completed, published, large-scale research makes the prospect more daunting and distant. It helped me gauge the size of project that is expected and see that other people have the same difficulties. Practice in protocol writing was useful. The course also helped to identify potential supervisors by their special interests.'

These views were echoed by another student:

'We had the opportunity to discuss each other's projects constructively. It helped to set limits and structure some of the projects more appropriately. Personally, I got a better understanding of what an MSc project should entail and ways of setting about it.'

A third student admired the informal atmosphere, the strong emphasis on feasibility, and the fact that lecturers were realistic without being 'off-putting'. This student added that the presentations had a personal flavour which added to the interest, and said he 'felt closer to his colleagues at the end of the course'.

\section{Comment}

In the past decade we have routinely evaluated our courses and we are therefore familiar with the usual range of responses to our teaching. The warmth of this feedback suggests that we have reduced our trainees' 'anxieties about carrying out their own project.

It is, of course, too early to say whether the new projects will actually be carried out, but there seems little doubt that the course has succeeded in its objective of giving a gentle push to those hesitating on the edge of the swimming pool. No unfavourable comments have been made about the format for each afternoon, so it is our intention to use the same format in subsequent years. The choice of topic areas must, of course, be determined by the teachers who are available and the nature of the research with which they are personally familiar.

It was perhaps inevitable that teachers revealed something of themselves in talking about their personal research interests, and this may account for the comment of the student who felt closer to his colleagues.

\section{Acknowledgement}

I wish to thank my colleagues who assisted me in teaching this course: Professor David Taylor, Dr. Michael Atkinson, Dr. Francis Creed, Dr. Donald Johnson, Dr Peter Maguire, Dr Frank Margison, Dr Keith Rix and Dr Elemir Szabadi.

\section{REFERENCES}

Crammer, J. (1979) Research in decline. Bulletin, November, pp 174-75.

Creed, F. \& Murray, R. (1981) Teaching of clinical skills. Psychological Medicine (in press)

LEw/s, A. (1961) Psychiatric education and training. Reprinted as Chapter 10 in The State of Psychiatry (1967). Routledge and Kegan Paul.

\title{
Children's Legal Centre
}

Michael Black, Consultant Psychiatrist in Bedfordshire, writes:

'I learned of the existence of the newly formed Children's Legal Centre while College representative to the International Year of the Child. The idea for the Centre came from a group of lawyers specializing in children's law because it was felt that the expertise of the relatively few lawyers working in this field needed to be made more widely available. The project was sponsored by the UK Association of the International Year of the Child in the hope that the work would continue after the year had ended. This is in fact the case, and fund raising is taking place to enable the Centre to establish itself on a permanent basis. The Centre will provide an advice service covering all matters concerning children and the law, and will also issue publications in order to spread information; hopes to organize courses for various professionals, and generally to increase levels of interest in knowledge of children's law.

The Centre expects to conduct research on specific issues and to provide evidence to parliamentary committees or government departments. It plans to undertake selected test cases in order to clarify the existing law. The Centre will also act as a resort to various groups in order to help them be more effective in their work with children and families. It expects to produce its own register of lawyers who have particular knowledge of children's law.

Some of the issues which may be of relevance to child psychiatrists include the importance of appropriate placement of a child who is in care, the need for such children to have a say in what happens to them, and the position of children in long-stay hospitals or other institutions. The Centre sees a need for child psychiatrists to be willing to act as independent experts with particular reference to care proceedings.'

For those child psychiatrists who are interested further information can be obtained from Naomi Angell or Rachel Hodgkin at: Children's Legal Centre, 2 Malden Road, London, NW5. 